\title{
Adjustable single incision sling Ajust - the effects of first operations controlled by pelvic floor sonography
}

\author{
Tomasz Kluz ${ }^{1}$, Edyta Wlaźlak² ${ }^{2}$ Andrzej Wróbel ${ }^{3}$, \\ Wiktor Wlaźlak ${ }^{2}$, Michał Pazdrak², Grzegorz Surkont ${ }^{2}$ \\ ${ }^{1}$ Department of Obstetrics and Gynecology, Fryderyk Chopin University Hospital No. 1, Faculty of Medicine, Rzeszow, Poland \\ ${ }^{2}$ Clinic of Operative Gynecology and Gynecologic Oncology, $1^{\text {st }}$ Department of Gynecology and Obstetrics, \\ Medical University of Lodz, Poland \\ ${ }^{3}$ Second Department of Gynecology, Medical University of Lublin, Poland
}

\begin{abstract}
Objective: The aim of this study is to evaluate using PFS-TV the mid-term results of our first operative experience with implanting a single incision sling - Ajust $^{\text {TM }}$.

Material and methods: One and the same surgeon has operated all the patients with symptoms of stress urinary incontinence. Ajust was the only performed procedure. Postoperative evaluation consisted of: a standardized interview and examination, a cough test and a PFS-TV for evaluation of urinary continence and tape location. PFS-TV was performed under standardized conditions at rest and during maximum Valsalva maneuver.

Results: This is a retrospective analysis of data from a total of 31 patients who attended a control visit between the $36^{\text {th }}$ and the $50^{\text {th }}$ month following the operation. Sixteen patients $(51.6 \%)$ were cured. There were statistically significant differences in urethral mobility $(p<0.0007)$ and tape-urethra distance $(p<0.002)$ between cured and not-cured group. The difference in urethral length was not statistically significant. $77.8 \%$ of women with a hypermobile urethra was cured in contrast to $15.4 \%$ with a normobile urethra. Neither of the groups had a hypomobile urethra patient. There were no significant complications intra- or post-operatively. De novo urgency was observed in 1 patient only.

Conclusions: Implantation of Ajust tape seems to be a safe mode of operative treatment for SUI in women. Our mid-term results suggest that long term effects might be worse compared to retropubic or transobturator tapes, especially at first operative experience with Ajust. Urethral mobility seems to be an important risk factor for treatment failure after Ajust implantation. It seems that patients that may benefit from Ajust most are women with urethral hypomobility but this needs to be verified with a prospective study.
\end{abstract}

Key words: stress urinary incontinence, mini-sling, suburethral sling, pelvic floor ultrasound, PFS-TV, transvaginal probe

Ginekologia Polska 2017; 88, 8: 407-413

\section{INTRODUCTION}

Stress urinary incontinence (SUI) is the most common type of urinary incontinence (UI) in women [1-4]. Although it may be treated conservatively, many women need to be operated [5]. Over 20 years ago it was suggested that mid-urethra played a pivotal role in achieving urinary continence. Suburethral retropubic tape TVT was then introduced and showed a high treatment efficacy with long lasting effects [5-11]. Introital pelvic floor sonography performed with a transvaginal probe (PFS-TV) showed to be useful in evaluating the implanted suburethral tapes. Studies based on PFS-TV have confirmed that results are best when the TVT tape is placed at the level of mid-urethra [12-14]. However, TVT implantation is associated with potential complications such as bladder perforation or vessel injuries so TVT gave ground to a transobturator tape (TOT) as alternative. The route of implantation of TOT allows to bypass the retropubic space, and hence to avoid many complications associated with TVT tape implantation [15]. PFS-TV has proved useful in visualizing the differences in biomechanical properties 
between TVT and TOT, which led to modifications of TOT implantation technique so to optimize the results $[12,13]$. Yet, after TOT implantation some other complications were observed such as thigh and groin pain, which usually has a very negative impact on patient's quality of life $[16,17]$. To avoid such complications a single-incision-mini-sling (SIMS) TVT-Secur $^{\mathrm{TM}}$ was introduced but poor midterm results have led to cessation of this product by the company [18].

There are differences between various SIMS. Ajust ${ }^{\mathrm{TM}}$ (C.R. Bard Inc., New Providence, NJ, USA) for instance should be anchored directly on the obturator muscle or membrane and it is possible to regulate the tension of this sling [19]. Ultrasound studies suggested that one year after implantation of SIMS, Ajust ${ }^{\mathrm{TM}}$ has the same quality of tape fixation as TVTO [20].

\section{OBJECTIVE}

The aim of this study is to evaluate using PFS-TV the mid-term results of SIMS Ajust ${ }^{\mathrm{TM}}$ implantation.

\section{MATERIAL AND METHODS}

All patients who were qualified for Ajust tape implantation had symptoms of SUI with significant impact on quality of life as the predominant compliant. One and the same experienced surgeon (T.K.) operated all of the patients included in this study.

Patients were examined pre-operatively under standardized conditions. Pelvic organ prolapse (POP) was classified in accordance with POP-Q system [21-25]. SUI was confirmed by a cough test [26].

Ajust implantations were performed according to a standardized technique [19]. Operations were performed under spinal epidural anesthesia. Foley catheter was removed a day after the operation and post-void residual was checked.

Postoperative evaluation consisted of: standardized interview and examination, cough test and PFS-TV to evaluate urinary continence, tape location and symmetry. If cough test performed in patients in lithotomy position was negative, it was repeated in standing.

Specialists experienced in pelvic floor ultrasound performed an ultrasound examination on GE Voluson $730 \mathrm{Ex}$ pert using a transabdominal transducer of $3.5 \mathrm{MHz}$ frequency and a transvaginal transducer of $6.5 \mathrm{MHz}$ frequency. The volume of urine in the bladder was evaluated during the transabdominal ultrasound by performing three-plane measurements of the bladder followed by calculations performed by the ultrasound system. We evaluated urinary continence, tape location and its symmetry in a condition where all patients had $250-350[\mathrm{~mL}$ ] of urine in the bladder. PFS-TV was performed introitally using a transvaginal probe of high-frequency $\left(6.5 \mathrm{MHz}, 160^{\circ}\right.$ beam angle ultra- sound) at rest and during maximum Valsalva maneuver, all in accordance to standardized conditions developed by Kociszewski $[12,13]$.

At the post-operative visit the length of urethra, urethral mobility and urethral funneling were evaluated during PFS-TV in a sagittal plane, as described previously $[12,13,25$, 26]. Urethral mobility was evaluated with a vector calculated from measurements obtained during PFS-TV according to the method specified by Viereck [13, 25]. A hypomobile urethra was defined as a vector value $\leq 5[\mathrm{~mm}]$, normobile urethra as a vector value between 5 and $15[\mathrm{~mm}]$, hypermobile urethra as a vector value $\geq 15[\mathrm{~mm}][13,14]$. We used the PFS-TV examination during Valsalva maneuver to observe urethral funneling with urine flow (long urethral funneling), which we regard as a confirmation of SUI reported by patients with a positive cough test (SUI+ group) (Figure 1) [26]. In the absence of clinical SUI symptoms or when the patient
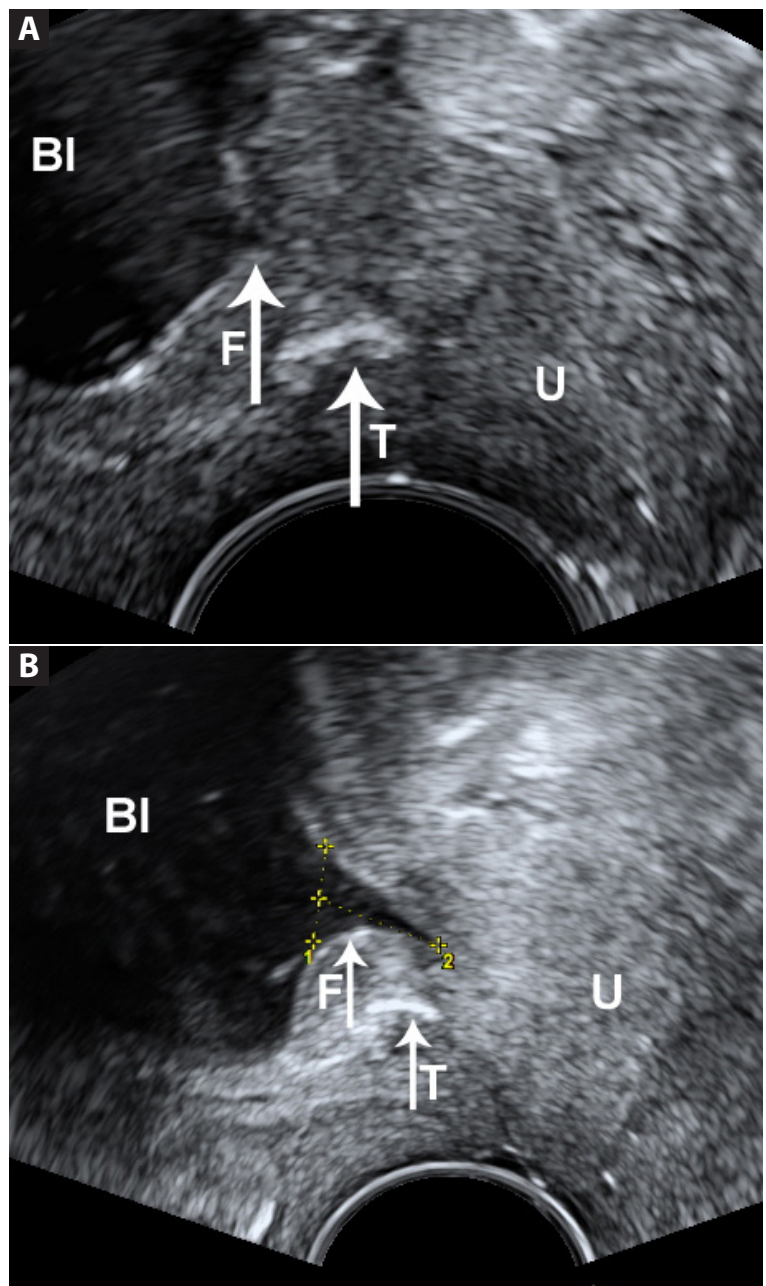

Figure 1. PFS-TV - evaluation of urethral funneling (sagittal plane). A. Short urethral funneling (without urine flow), tape cured SUI; B. Long urethral funneling (with urine flow), tape did not cure SUI. Legend: $\mathrm{BI}$ — bladder, $\mathrm{U}$ - urethra, arrow T — tape, arrow - funneling (in agreement with the technique first introduced by J. Kociszewski [26]) 
observed SUI only periodically with a negative sitting and standing cough test we diagnosed no SUI. In these patients no signs of SUI during PFS-TV was found. Namely, there was either no urethral funneling or the urethral funneling was on short distance but there was no urine flow (short urethral funneling). Such patients make up the SUI0 group (Figure 1) [26]. J. Kociszewski was first who introduced the technique of ultrasound evaluation of urethral funneling as well as concept of short and long urethral funneling, which we used in the study [26].

The location of Ajust sling was defined during PFS-TV in a sagittal plane similarly to the measurements proposed by Kociszewski et al. (Figure 2) $[12,13]$. The shortest distance between the tape and the hypoechoic urethra was measured in [mm]. It was called a tape-urethra distance. Next, we
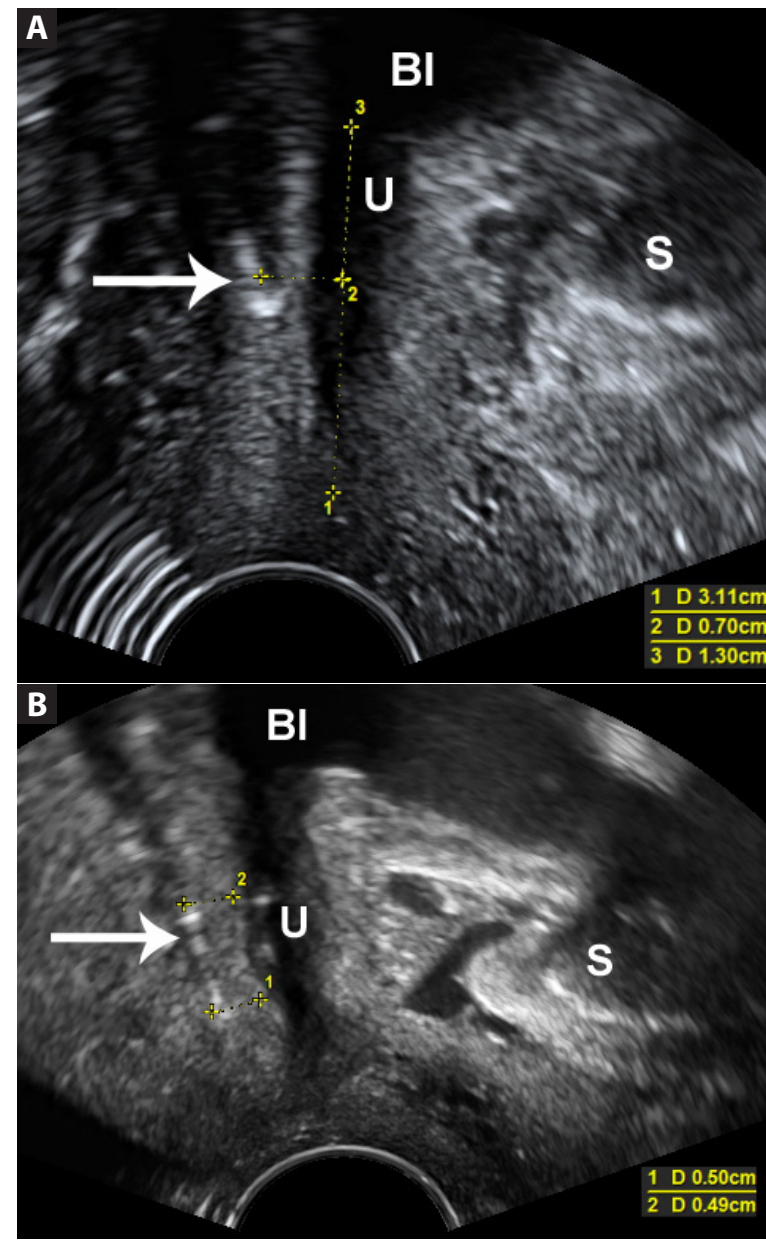

Figure 2. PFS-TV — evaluation of tape location (sagittal plane). A. Relative tape position: $13,0 \mathrm{~mm} \times 100 / 31.1 \mathrm{~mm}=41.8 \%$. Legend: 1 - urethral length, 2 - reflects the position of middle part of the tape on the axis of the urethra, 3 - distance of the middle part of the tape from the bladder neck, $\mathrm{BI}$ - bladder, $\mathrm{U}$ - urethra, $\mathrm{S}$ - symphysis pubis, arrow - tape; $\mathbf{B}$. Tape-urethra distance $-4.9 \mathrm{~mm}$. Legend: 1 - maximal distance between the tape and the hypoechoic urethra, 2 - minimal distance between the tape and the hypoechoic urethra - tape-urethra distance, $\mathrm{BI}$ - bladder, $\mathrm{U}$ - urethra, $\mathrm{S}$ - symphysis pubis, arrow - tape calculated the tape position relative to the urethral length in\% according to the following formula (1):

Relative tape position $=$ distance of the middle part o the tape from the bladder neck $\times 100 \%$ /sonographic urethral length.

The symmetry of the tape was analyzed in axial plane. Statistical analysis was carried out using STATISTICA 7.0 of StatSoft. Median, arithmetic mean and standard deviations were calculated. Student's t-test was applied for testing the significance of differences for dependent variables.

\section{RESULTS}

This study is a retrospective analysis of data from 31 patients (a total of operated patients $=39$ ) that attended a control visit between the $36^{\text {th }}$ and the $50^{\text {th }}$ month following the operation. The mean age of patients was 59.5 years (range $=44-80)$, mean BMI was $28.8 \mathrm{~kg} / \mathrm{m}^{2}$ (range $=21.5-$ -36.5 ), mean parity was 2 (range $=1-5$ ). The majority of women have had a spontaneous delivery. Two women had a caesarean section apart of 2 and 4 spontaneous deliveries, respectively. One patient had vacuum apart from a spontaneous delivery. There were no statistically significant differences in age, BMI or parity between groups SUIO and $\mathrm{SUI}+$. Ten women were on anti-hypertensive drugs and one patient was on insulin. Three women suffered from asthma. Five women had hysterectomy in the past: four abdominal and one - vaginal. One patient had previously a vaginal repair surgery and one had Burch colposuspension procedure.

All of the women had SUI with a considerable impact on their quality of life and none had clinically significant vaginal prolapse. The Ajust tape implantation was the only treatment implemented. At the control visit the treatment was successful (SUI0) in 16 patients (51.6\%) and unsuccessful (SUI+) in 15 (48.4\%) patients. Before the operation a total of 11 women had symptoms of overactive bladder (OAB) and none of them were treated pharmacologically. After the operation, in 8 cases out of 11 the OAB symptoms have persisted. One patient has observed urgency de novo after surgery.

Statistically significant differences between SUI0 group and SUI+ group postoperatively concern the urethral mobility $(p<0.0007)$ and the tape-urethra distance $(p<0.002)$. The difference in urethral length or relative tape position between the groups was not statistically significant.

The median value of the urethral mobility vector was 22.9 [mm] (range $=8.0-34.3$ ) for SUI0 group and $11.9[\mathrm{~mm}]$ (range $=6.5-21.4$ ) for SUI+ group, while the median tape-urethra distance was $3.5[\mathrm{~mm}]$ (range $=1.9-6.1$ ) and 6.1 [mm] (range $=2.5-8.5$ ), respectively. There was no case of a hypomobile urethra (vector value $\leq 5 \mathrm{~mm}$ ) in neither of the groups (Figure 3 ).

The median of urethral length was 30.1 [mm] (range $=24.3-38.1)$ for SUI0 group and $28.2[\mathrm{~mm}](21.6-36.8)$ 
A

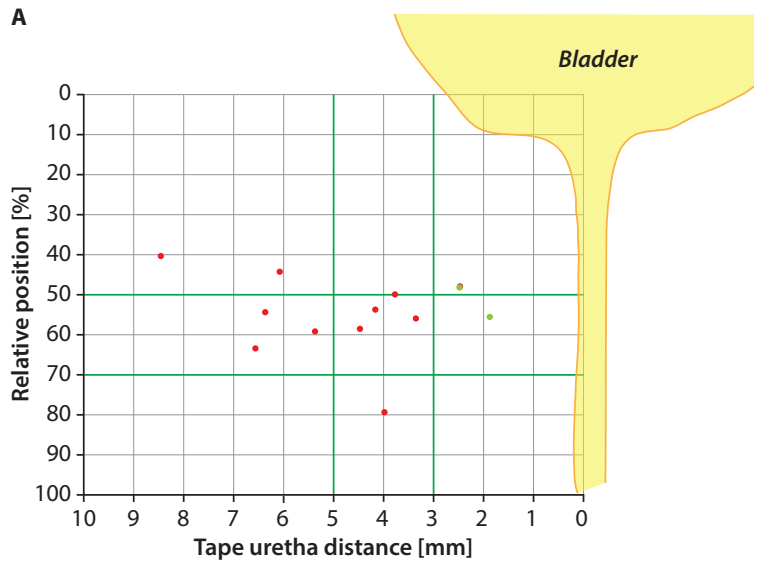

B

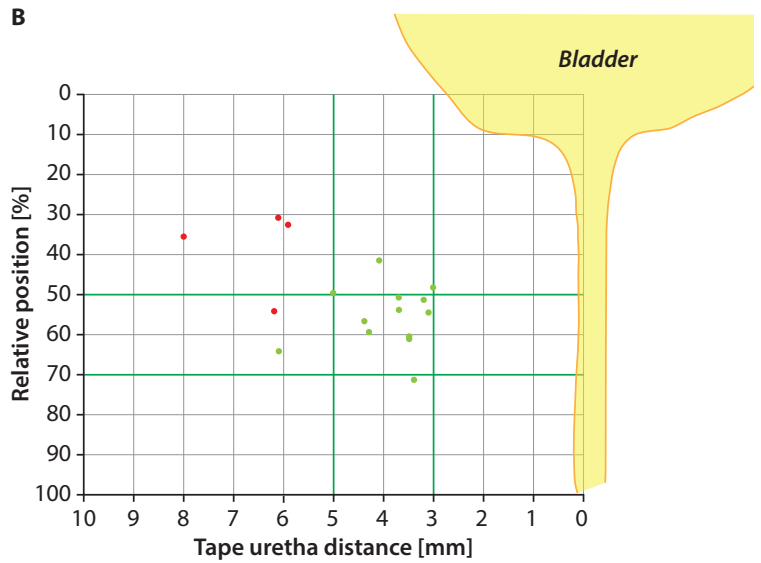

Figure 3. The SUI treatment results after Ajust implantation with respect to prior urethral mobility. A. In women with urethral normobility (vector value $5 \mathrm{~mm}<$ and $<15 \mathrm{~mm}$ ); B. In women with hypermobility (vector value $\geq 15 \mathrm{~mm}$ ). Legend: • cured (SUIO), • not-cured (SUI+)

for $\mathrm{SUI}+$ group, while the relative tape position was $55.8 \%$ (range $=41.5-71.2 \%)$ and $51.3 \%$ (range $=30.7-79.3 \%$ ), respectively to the group.

A normobile urethra ( $5 \mathrm{~mm}<$ vector value $<15 \mathrm{~mm}$ ) was observed in thirteen women (41.9\%). The treatment was successful (SUI0) for only 2 patients (15.4\%) from this group. Their respective tape-urethra distance was 1.9 and $2.5[\mathrm{~mm}]$. Despite a small sample, the differences in tape-urethra distance between groups SUIO and SUI+ were quite close to statistically significant $(p=0.07)$. The tape-urethra distance in case of failed treatment (SUI+ group) was lower than $5[\mathrm{~mm}]$ in $45.5 \%$ of cases and higher than 5 [mm] (up to 8.5 [mm]) in the rest of the cases, with a mean value of $5.2[\mathrm{~mm}]$. The relative tape position in groups SUI+ and SUIO was similar and amounted to $55.6 \%$ and $52.2 \%(p=0.72)$, respectively (Figure 3). In Figure 3 we used the way of presentation, as well as values of optimal tape position and tape-urethra distance, published earlier in the literature by Kociszewski, Viereck et al. [12-14, 25].

A hypermobile urethra (vector value $\geq 15[\mathrm{~mm}]$ ) was observed in a total of eighteen women (58.1\%), of which fourteen $(77.8 \%)$ were treated successfully (SUI0). In this group the tape-urethra distance was $\leq 5[\mathrm{~mm}]$ except one case of 6.1 [mm]. In most of patients from SUI0 group the relative tape position was between $50 \%$ and $70 \%$. In 2 cases it was between $40 \%$ and $50 \%$. In one case it was $71.2 \%$ with a tape-urethra distance of 3.4 [mm]. Out of the remaining hypermobile urethra patients 4 fell into the treatment failure group (SUI+), of which 3 had a relative tape position between $30 \%$ and $35 \%$ meaning that the tape was positioned to close to the neck of the bladder. In such case the tape-urethra distance was between $5.9[\mathrm{~mm}]$ and $8.0[\mathrm{~mm}]$. The remaining case had a relative tape position of $54 \%$ and a tape-urethra distance of 6.2 [mm]. The differences in values of relative tape position between hypermobile urethra patients in groups SUI+ and SUI0 were statistically significant: $56.1 \%$ vs. $38.2 \%$ ( $p$ < 0.004). In 3 cases of failed treatment the value was between $30 \%$ and $36 \%$ (Figure 3 ).

During PFS-TV we detected: 2 cases of tape being rolled-up (Figure 4), 1 case of tape detachment from a side and 3 cases of the tape being positioned asymmetrically around the urethra (Figure 5).

\section{DISCUSSION}

Studies showed that a TVT retropubic tape has some very good long-term results. Results of 17 years follow-up report that over $90 \%$ of women were objectively continent and $87 \%$ were subjectively cured or improved significantly [8]. Recently, some published studies and meta-analysis have suggested that mid-term results of TVT and TOT maybe quite similar [17, 27]. Complications after TVT and TVTO have led to the introduction of first SIMS - the TVT Secur ${ }^{\mathrm{TM}}$. However, the effects of SIMS implantation seem to fall short of expectations, especially at a longer time perspective [18].

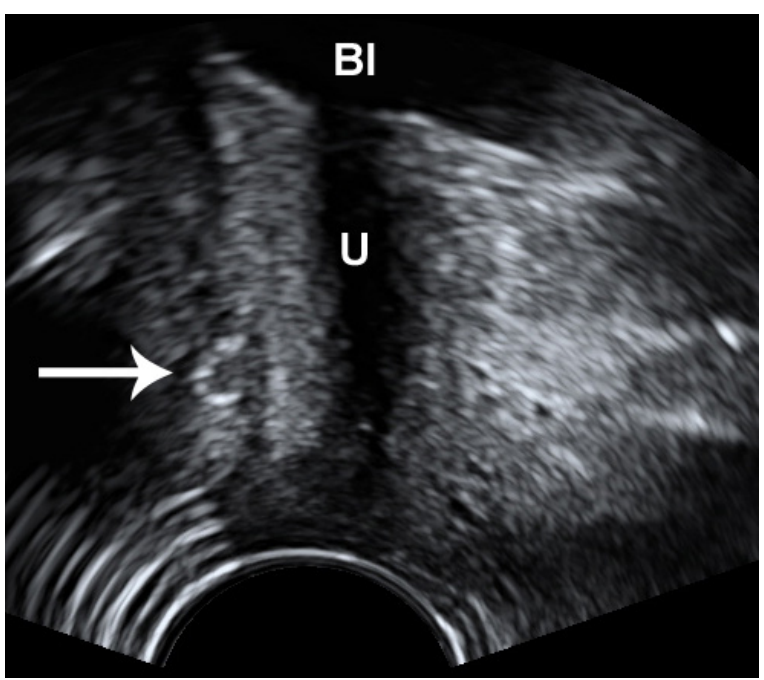

Figure 4. PFS-TV — rolled-up tape (sagittal plane) 

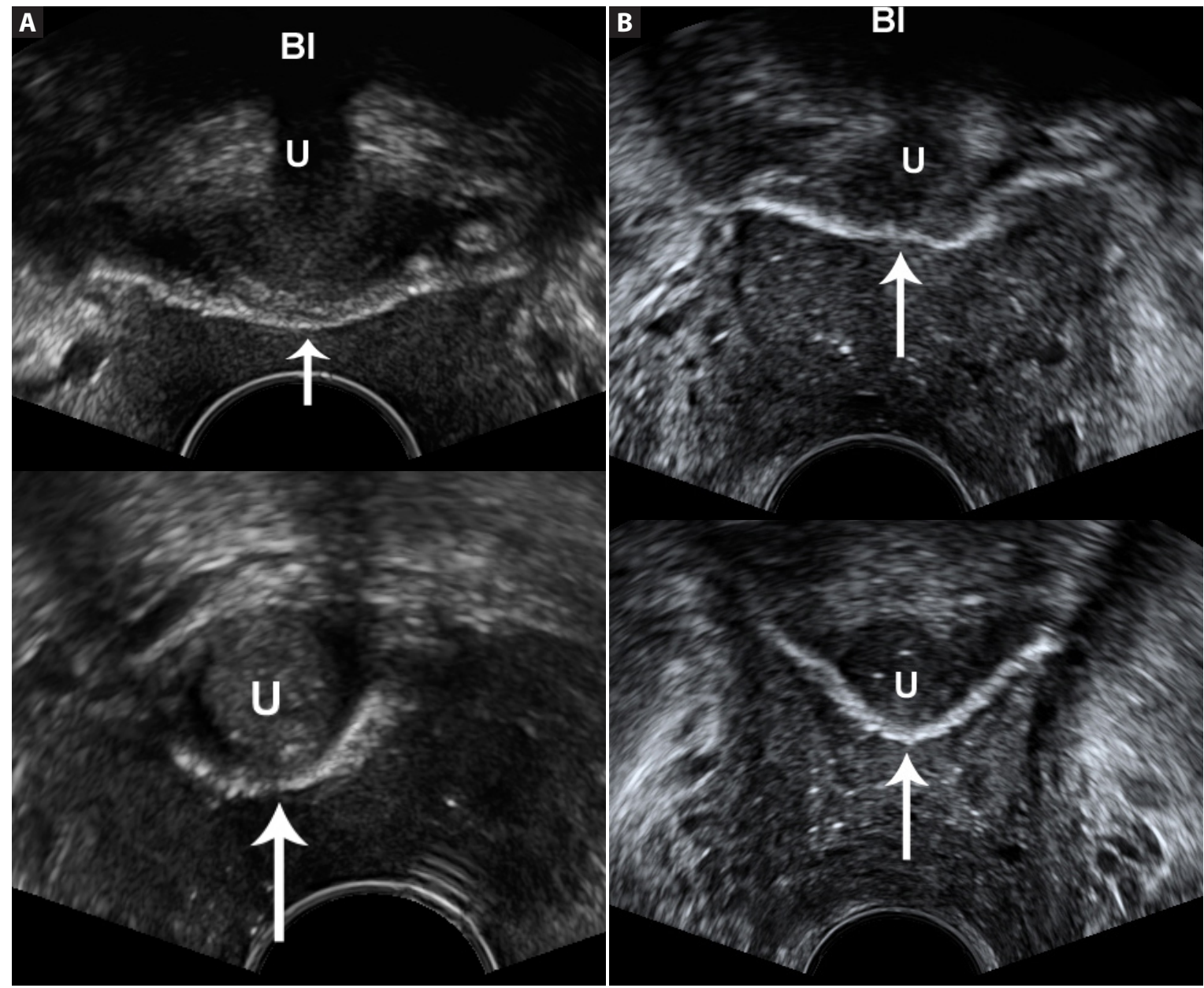

Figure 5. PFS-TV — tape symmetry analysis in axial plane. A. Symmetric tape; B. Asymmetric tape

Nowadays, there are a few SIMS available on the market, all of which are made of polypropylene. Yet, they differ, which may have an influence on biomechanical properties of tapes and on their respective cure rate [19,20,28]. Various success rates have been reported for SIMS during the last decade [26, 27]. PFS-TV examination proved useful in detecting some of the differences in biomechanical properties between TVT and TVTO. For instance, it was noted that in order to achieve optimal results different place of incision is advised, i.e. formula 1/2 for TVTO and formula 1/3 for TVT $[12,13]$.

SIMS has some unquestionable advantages such as avoiding complications that are typical forTVT and TVTO like pain or injury in retropubic or transobturator spaces. Also, a smaller polypropylene tape is implanted [28]. The Ajust sling is the first SIMS, which just like TOT anchors to the obturator muscle or its membrane complex. During the procedure it is possible to adjust the tension of the tape [19]. Studies suggest that leaving a slight tension at the midurethra can improve the outcome [29]. It is also possible to loosen the TVT tape during the first few days after the procedure [30]. Yet, we did not find any information about it in the literature. In our patients there was no need to perform a procedure of loosening the sling since there was no case of permanent post-void residual. However, we recognize this as a potential problem since studies recommend placing SIMS with a slight tension.

Studies report a cure rate from SUI symptoms after 12-29 months from inserting Ajust sling to be $80.0-84.7 \%$ [19,31-34]. After Ajust implantation a statistically significant increase of Pdet and decrease of Qmax during voiding phase was observed in urodynamics. Yet, there were no signs of obstruction [19]. De novo urgency was noted in 7.8-21.7\% of patients and de novo urge incontinence was noted in $6.5 \%$ of patients $[19,33,34]$. In turn, after $3-5$ years from Ajust implantation $51.6 \%$ of women from our study population are reported as cured. De novo urgency was observed in 1 patient only (3.2\%). We have no clear explanation for the difference between the results quoted in the literature and those of our study. We may only hypothesize a few reasons for such difference. Firstly, our study concerns first operative experience with Ajust so it may simply be the consequence of a learning curve. Secondly, studies suggest 
that SIMS should be implanted with a little more tension than TVT [19, 31-34]. PFS-TV studies on TVT placement showed that a tape, which is positioned too close to the urethra (tape-urethra distance $<3 \mathrm{~mm}$ ) maybe responsible for a higher risk of urgency de novo and a post-void residual [12, 13]. In contrast to the results of other studies, only 1 patient informed about urgency de novo in our study population. It could be then that we had inserted the tape less tightly than other authors, which has yielded a lower cure rate but at the same time a lower rate of urge de novo.

In previous studies Kociszewski et al. showed that optimal therapeutic window for both TVT and TVTO lies between 3 and 5 [mm] for the tape urethra distance and between $50 \%$ and $70 \%$ for the relative tape position. Failure rate for both tapes depends also on prior urethral mobility [12-14].TOT implantation treated successfully $0 \%, 72 \%$ and $88 \%$ of patients with hypomobile, normobile and hypermobile urethra, respectively. TVT cured respectively $67 \%$, $76 \%$ and $100 \%$ of patients with hypomobile, normobile and hypermobile urethra. In the hypomobile urethra group the optimal tape-urethra distance for TVT was not 3-5 [mm] but $2.5-3.5[\mathrm{~mm}]$, while in the hypermobile group it was 3-7 [mm]. Our study in turn indicates that for Ajust tape the optimal tape-urethra distance is $\leq 2.5$ [mm] and $3-5[\mathrm{~mm}]$, respectively for normobile and hypermobile urethra patients. These results need to be confirmed with a larger population study, preferably a prospective one. Our relative tape position in most cases was between 50 and $70 \%$, which means no conclusions can be drawn with respect to an optimal therapeutic window for Ajust tape. Our results confirm that tape location near the bladder neck (relative tape position $<40 \%$ ) is often the reason for failure.

The follow-up period could also be the reason for the high percentage of treatment failure since our study follow-up period is considerably longer than that of other publications concerning Ajust tape. In a study comparing SIMS Miniarc with a retropubic tape the cure rate after 3 years from tape implantation was $47.4 \%$ for Miniarc vs. $91 \%$ for a retropubic tape [35]. However, authors did not mention tape-urethra distance or relative tape position.

The adverse results in our study include 2 cases of tape rolling up and 1 case of tape detachment from a side. In 3 cases the tape was positioned asymmetrically. This may be due to the learning curve but short tape making the optimal positioning even more difficult is also an option. So far only one study in the literature has evaluated Ajust tape with ultrasound. The authors did not mention to encounter similar problems [20].

We found no studies similar to ours that would analyze the SIMS location, the urethral mobility and eventual treatment success rates.
Similarly to other studies we did not observe any signifcant intraoperative or postoperative complications [19, 31-34].

Our study has some limitations. This is a retrospective study based on only first operative experience with Ajust while the number of patients is low. On the other hand only one and the same experienced surgeon performed the operations so the results may be close to the results obtained during first procedures in real clinical practice. Also, we have used PFS-TV so to objectively evaluate the postoperative continence as well as the tape location. This is the first study concerning SIMS where the effect of tape location was analyzed in light of the urethral mobility. In our opinion there is a high need to perform prospective comparative studies (SIMS vs. TVT or TOT) with a long observational period using ultrasound as one of the control method since our study confirms that there may be quite important differences between the available tapes and that the ultrasound examination may be an optimal universal tool for their evaluation and comparison.

\section{CONCLUSIONS}

Implantation of Ajust tape seems to be a safe mode of operative treatment of SUI in women. Our mid-term results suggest that the long-term effects might be worse than that of retropubic or transobturator tapes, especially at first operative experience with Ajust. Urethral mobility seems to be an important risk factor for a treatment failure after Ajust implantation. It is possible that patients that may benefit from Ajust most are women with urethral hypomobility but this needs to be verified with a prospective study.

\section{REFERENCES}

1. WlaźlakE, Surkont G, Shek KaL, et al. Can we predict urinary stress incontinence by using demographic, clinical, imaging and urodynamic data? Eur J Obstet Gynecol Reprod Biol. 2015; 193: 114-117, doi: 10.1016/j. ejogrb.2015.07.012, indexed in Pubmed: 26291686.

2. Surkont G, Wlaźlak E, Suzin J. Urinary incontinence in women - social, medical and scientific problem. Menopause Rev. 2003; 1: 59-65.

3. Surkont G, Wlaźlak E, Dunicz-Sokolowska A, et al. [The efficacy of SUI treatment with Burch colposuspension evaluated with use of ITT anaIysis]. Ginekol Pol. 2007; 78(5): 378-380, indexed in Pubmed: 17867329.

4. Stangel-Wojcikiewicz K, Petko M, Kobus K, et al. Regenerative medicinetechniques and methods of administering autologous derived stem cells in urinary incontinence. Ginekol Pol. 2016; 87(3): 205-210, doi: 10.17772/gp/60973, indexed in Pubmed: 27306130.

5. Sandvik H, Hunskaar S, Vanvik A, et al. Diagnostic classification of female urinary incontinence: an epidemiological survey corrected for validity. J Clin Epidemiol. 1995; 48(3): 339-343, indexed in Pubmed: 7897455.

6. Ulmsten U. Some reflections and hypotheses on the pathophysiology of female urinary incontinence. Acta Obstet Gynecol Scand Suppl. 1997; 166: 3-8.

7. Ulmsten $\mathrm{U}$, Johnson P, Rezapour M. A three-year follow up of tension free vaginal tape for surgical treatment of female stress urinary incontinence. Br J Obstet Gynaecol. 1999; 106(4): 345-350, indexed in Pubmed: 10426241

8. Nilsson CG, Palva K, Aarnio R, et al. Seventeen years' follow-up of the tension-free vaginal tape procedure for female stress urinary incontinence. Int Urogynecol J. 2013; 24(8): 1265-1269, doi: 10.1007/s00192013-2090-2, indexed in Pubmed: 23563892. 
9. Surkont G, Wlaźlak E, Petri E, et al. Standardized modified colposuspension - mid-term results of prospective studies in one centre. Ann Agric Environ Med. 2015; 22(2): 293-296, doi: 10.5604/12321966.1152082, indexed in Pubmed: 26094526.

10. Surkont G, Wlaźlak E, Suzin J. Long-term risk of complications after mid-urethral sling IVS implantation. Ann Agric Environ Med. 2015; 22(1): 163-166, doi: 10.5604/12321966.1141388, indexed in Pubmed: 25780848.

11. Surkont G, WlazlakE, Kazimierak W, et al. [The influence of SUI operative treatment with use of IVS tape on quality of life]. Ginekol Pol. 2007; 78(5): 381-383, indexed in Pubmed: 17867330.

12. Kociszewski J, Rautenberg O, Kuszka A, et al. Can we place tension-free vaginal tape where it should be? The one-third rule. Ultrasound Obstet Gynecol. 2012; 39(2): 210-214, doi: 10.1002/uog.10050, indexed in Pubmed: 21793084.

13. Viereck V, Kuszka A, Rautenberg O, et al. Do different vaginal tapes need different suburethral incisions? The one-half rule. Neurourol Urodyn. 2015; 34(8): 741-746, doi: 10.1002/nau.22658, indexed in Pubmed: 25176293.

14. Wlaźlak E, Viereck V, Kociszewski J, et al. Role of intrinsic sphincter deficiency with and without urethral hypomobility on the outcome of tape insertion. Neurourol Urodyn. 2017 [Epub ahead of print], doi: 10.1002/nau.23211, indexed in Pubmed: 28139863.

15. Delorme E, Droupy S, de Tayrac R, et al. Transobturator tape (Uratape): a new minimally-invasive procedure to treat female urinary incontinence. Eur Urol. 2004; 45(2): 203-207, indexed in Pubmed: 14734007.

16. Abdel-Fattah M, Cao G, Mostafa A. Long-term outcomes for transobturator tension-free vaginal tapes in women with urodynamic mixed urinary incontinence. Neurourol Urodyn. 2017; 36(4): 902-908, doi: 10.1002/nau.23192, indexed in Pubmed: 28028822.

17. Leone Roberti Maggiore U, Finazzi Agrò $\mathrm{E}$, Soligo $\mathrm{M}$, et al. Long-term outcomes of TOT and TVT procedures for the treatment of female stress urinary incontinence: a systematic review and meta-analysis. Int Urogynecol J. 2017; 28(8): 1119-1130, doi: 10.1007/s00192-017-3275-x, indexed in Pubmed: 28213797.

18. Cornu JN, Sèbe P, Peyrat L, et al. Midterm prospective evaluation of TVT-Secur reveals high failure rate. Eur Urol. 2010; 58(1): 157-161, doi: 10.1016/j.eururo.2010.04.021, indexed in Pubmed: 20434258.

19. Natale F, Dati S, La Penna C, et al. Single incision sling (Ajust ${ }^{\mathrm{TM}}$ ) for the treatment of female stress urinary incontinence: 2-year follow-up. Eur J Obstet Gynecol Reprod Biol. 2014; 182: 48-52, doi: 10.1016/j. ejogrb.2014.08.011, indexed in Pubmed: 25233444.

20. Farhat F, Švabík K, Hubka P, et al. [Ultrasound comparison of adjustable single-incision (Ajust) and transobturator tapes to assess post-operative fixation and function and clinical efficacy]. Ceska Gynekol. 2016; 81(5): 324-335, indexed in Pubmed: 27897018.

21. Bump RC, Mattiasson A, BøK, et al. The standardization of terminology of female pelvic organ prolapse and pelvic floor dysfunction. Am J Obstet Gynecol. 1996; 175(1): 10-17, indexed in Pubmed: 8694033.

22. Lemos $\mathrm{N}$, Korte JE, Iskander M, et al. Center-by-center results of a multicenter prospective trial to determine the inter-observer correlation of the simplified POP-Q in describing pelvic organ prolapse. Int Urogynecol J. 2012; 23(5): 579-584, doi: 10.1007/s00192-011-1593-y, indexed in Pubmed: 22083515.

23. Parekh M, Swift S, Lemos $\mathrm{N}$, et al. Multicenter inter-examiner agreement trial for the validation of simplified POPQ system. Int Urogynecol J.
2011; 22(6): 645-650, doi: 10.1007/s00192-011-1395-2, indexed in Pubmed: 21431391.

24. Staskin D, Kelleher C, Avery K. et al. Initial Assessment of Urinary and Faecal Incontinence in Adult Male and Female Patients. In: Abrams P, Cardozo L, Khoury S, Wein A. ed. Incontinence. Health Publication Ltd 2009: 331-412.

25. Viereck V, Pauer HU, Hesse O, et al. Urethral hypermobility after anti-incontinence surgery - a prognostic indicator? Int Urogynecol J Pelvic Floor Dysfunct. 2006; 17(6): 586-592, doi: 10.1007/s00192-006-0071-4, indexed in Pubmed: 16538422.

26. Bergström BoS. Curative mechanisms of two tension-free vaginal tape positions. Theoretical comments based on the urethral hanging theory of female stress urinary incontinence. Neurourol Urodyn. 2017 [Epub ahead of print], doi: 10.1002/nau.23229, indexed in Pubmed: 28185298.

27. Serati M, Braga A, Athanasiou S, et al. Tension-free Vaginal Tape-Obturator for Treatment of Pure Urodynamic Stress Urinary Incontinence: Efficacy and Adverse Effects at 10-year Follow-up. Eur Urol. 2017; 71(4): 674-679, doi: 10.1016/j.eururo.2016.08.054, indexed in Pubmed: 27597239.

28. Mostafa A, Lim CP, Hopper $L$, et al. Single-incision mini-slings versus standard midurethral slings in surgical management of female stress urinary incontinence: an updated systematic review and meta-analysis of effectiveness and complications. Eur Urol. 2014; 65(2): 402-427, doi: 10.1016/j.eururo.2013.08.032, indexed in Pubmed: 24055431.

29. Schellart RP, Oude Rengerink K, Van der Aa F, et al. A randomized comparison of a single-incision midurethral sling and a transobturator midurethral sling in women with stress urinary incontinence: results of 12-mo follow-up. Eur Urol. 2014; 66(6): 1179-1185, doi: 10.1016/j. eururo.2014.07.027, indexed in Pubmed: 25168619.

30. Rautenberg $\mathrm{O}$, Kociszewski J, Welter J, et al. Ultrasound and early tape mobilization - a practical solution for treating postoperative voiding dysfunction. Neurourol Urodyn. 2014; 33(7): 1147-1151, doi: 10.1002/nau.22459, indexed in Pubmed: 23818418.

31. Cornu JN, Peyrat L, Skurnik A, et al. Ajust single incision transobturator sling procedure for stress urinary incontinence: results after 1-year follow-up. Int Urogynecol J. 2012;23(9): 1265-1270, doi: 10.1007/s00192012-1740-0, indexed in Pubmed: 22584919.

32. Abdel-Fattah $\mathrm{M}$, Agur $\mathrm{W}$, Abdel-All $\mathrm{M}$, et al. Prospective multi-centre study of adjustable single-incision mini-sling (Ajust $\left.{ }^{\oplus}\right)$ ) in the management of stress urinary incontinence in women: 1-year follow-up study. BJU Int. 2012; 109(6): 880-886, doi: 10.1111/j.1464-410X.2011.10471.x, indexed in Pubmed: 21883844.

33. Naumann G, Hagemeier T, Zachmann S, et al. Long-term outcomes of the Ajust Adjustable Single-Incision Sling for the treatment of stress urinary incontinence. Int Urogynecol J. 2013; 24(2): 231-239, doi: 10.1007/s00192-012-1843-7, indexed in Pubmed: 22707009.

34. Grigoriadis C, Bakas P, Derpapas A, et al. Tension-free vaginal tape obturator versus Ajust adjustable single incision sling procedure in women with urodynamic stress urinary incontinence. Eur J Obstet Gynecol Reprod Biol. 2013; 170(2): 563-566, doi: 10.1016/j.ejogrb.2013.07.041, indexed in Pubmed: 23972452.

35. Basu M, Duckett J. Three-year results from a randomised trial of a retropubic mid-urethral sling versus the Miniarc single incision sling for stress urinary incontinence. Int Urogynecol J. 2013; 24(12): 2059-2064, doi: 10.1007/s00192-013-2125-8, indexed in Pubmed: 23712578. 